\title{
Ride performance analysis of half-car model for semi-active system using RMS as performance criteria
}

\author{
S. I. Ihsan ${ }^{\mathrm{a}}$, M. Ahmadian ${ }^{\mathrm{b}}$, Waleed F. Faris ${ }^{\mathrm{a}, *}$ and E. D. Blancard ${ }^{\mathrm{b}}$ \\ ${ }^{a}$ Mechanical Engineering Department, College of Engineering, International Islamic University Malaysia (IIUM), \\ Malaysia \\ ${ }^{\mathrm{b}}$ Mechanical Engineering Department, Virginia Tech, Blacksburg, VA, USA
}

Received 25 April 2008

Accepted 15 October 2008

\begin{abstract}
The work aims to study the root mean square (RMS) responses to acceleration input for four state variables: the $\mathrm{m}_{s}$ vertical acceleration, the $\mathrm{m}_{s}$ pitch angular acceleration and the front and rear deflections of the suspensions. A half-car two degree-of-freedom model of semi-active control scheme is analyzed and compared with the conventional passive suspension system. Frequency response of the transfer function for the heave, pitch of the sprung mass and suspension deflections are initially compared and then mean square analysis is utilized to see the effect of semi-active scheme. Results indicate that significant improvements were achieved in the sprung mass heave and pitch responses using semi-active control scheme. However results for the rear and front suspension deflection show that there are limiting values of damping coefficient beyond which, the semi-active scheme becomes disadvantageous than the passive system.
\end{abstract}

Keywords: RMS, semi-active system, passive suspension system, ride comfort, control systems, Performance criteria

\section{Introduction}

Suspension systems are often used to control response of various rigid and flexible multi-body systems [1,2]. The most common area of application of suspension systems is in vehicular applications, where they are used particularly to control the tire deflection or wheelhop for handling performance and vehicle body deflection and acceleration for passenger ride comfort [3].

Since first introduced by Crosby and Karnopp [4,5], semiactive suspension systems continue to gain considerable attention in vehicle applications. This is due to its advantageous characteristics over passive system in overcoming the traditional conflict between vehicle safety and handling, and ride comfort, as well as its significantly less in complexity and power requirement than active suspension system [6-8]. Semiactive dampers draw small amounts of energy to operate a valve to adjust the damping level and thus reduce the amount of vibration energy transmitted from the source to the vehicle body.

Semiactive dampers can generally be classified based on their control scheme as on-off skyhook, continuous skyhook, on-off groundhook or continuous groundhook. Skyhook control is known to be able to improve the vehicle body resonance, but at the expense of the tire resonance (wheelhop), while groundhook control provides a better control of tire resonance, but at the expense of increasing vehicle body resonance. Hybrid control, which combine

\footnotetext{
*Corresponding author. E-mail: waleed@iiu.edu.my.
} 


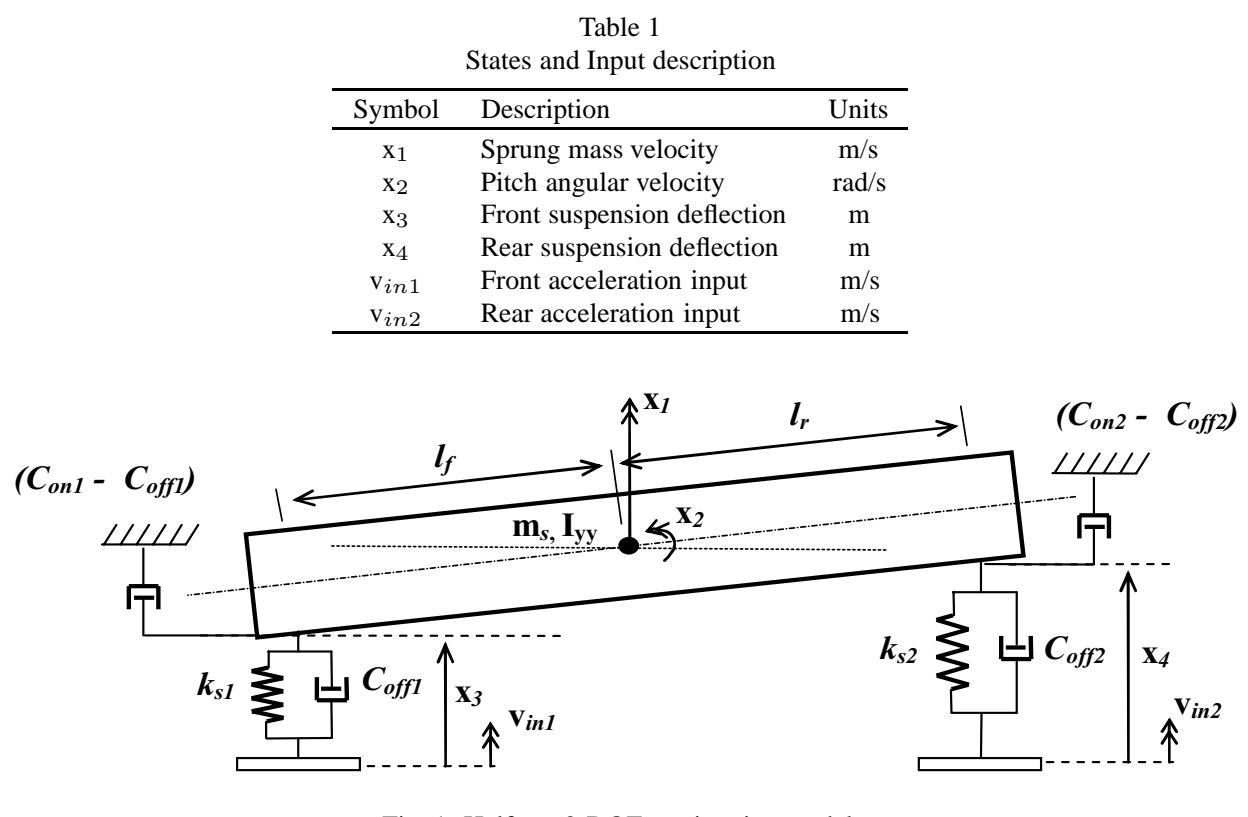

Fig. 1. Half-car 2-DOF semi-active model.

the effect of both skyhook and groundhook has been introduced and shown to provide a compromise between the two while still performing better than the passive system $[9,10]$.

The work aims to study the root mean square (RMS) responses to acceleration input for four state variables: the $m_{s}$ vertical acceleration, the $m_{s}$ pitch angular acceleration and the front and rear deflections of the suspensions. The RMS values for the first two variables can be used as a measure of vibration isolations for $m_{s}$ vertical and pitch motion, and the third and fourth as a measure of the rattle space requirement. The performance of semi-active control policy and conventional passive system is compared. Mean square values of the response are used as the performance criteria in improving the ride comfort of the system. It is therefore assumed that reducing the overall response (rms value) of the system generally reduce the discomfort level of passengers, thus improving the ride comfort.

This mean squares approach is utilized by many, including Asami and Nishihara [11] in their work in reducing the overall vibration transfer and later used by Blanchard [10] as the performance criteria in improving the ride comfort of a quarter-car model system. This work in a way is an extension of the work done by Blanchard [10].

The comparison between different semi-active suspensions systems have been extensively covered by Ihsan et al. [12,13] but without using RMS as a performance criteria and the main objective of these papers were to look into the dynamics of the systems under different controllers.

A half-car two degree-of-freedom (DOF) model is used in this analysis. This model includes two suspension systems that connect at each end of a body (sprung mass with heave and pitch motions), representing a half of the vehicle body, and two inputs. A linearized approach, which has been used by many [1-3,10,11], is used here as well. The inputs can be thought as the output of the road disturbance input to the tire system. Thus, the semi-active control system of this model can be regarded as closely resemble a skyhook control scheme.

\section{Modeling and analysis}

A general half-car model is used in this analysis as shown in Fig. 1. From this single model, both semi-active control scheme and passive system can be derived. The state variables and input descriptions are provided in Table 1 .

The equations of motion derived from the model are shown below:

$$
\begin{aligned}
& m_{s} \dot{x}_{1}+k_{s 1} x_{3}+k_{s 2} x_{4}+c_{o f f 1} \dot{x}_{3}+c_{o f f 2} \dot{x}_{4}+\left(c_{o n 1}-c_{o f f 1}\right)\left(\dot{x}_{3}+v_{i n 1}\right) \\
& \quad+\left(c_{o n 2}-c_{o f f 2}\right)\left(\dot{x}_{4}+v_{i n 2}\right)=0
\end{aligned}
$$




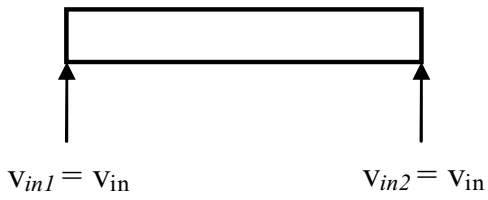

(a) Heave Input

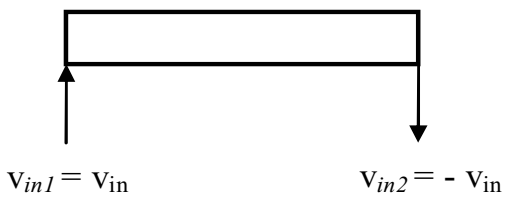

(b) Pitch Input

Fig. 2. Types of input signals used.

$$
\begin{aligned}
& I_{y y} \dot{x}_{2}-k_{s 1} x_{3} l_{f}+k_{r 1} x_{4} l_{r}-c_{o f f 1} \dot{x}_{3} l_{f}+c_{o f f 2} \dot{x}_{4} l_{r} \\
& \quad-\left(c_{o n 1}-c_{o f f 1}\right)\left(\dot{x}_{3}+v_{i n 1}\right) l_{f}+\left(c_{o n 2}-c_{o f f 2}\right)\left(\dot{x}_{4}+v_{i n 2}\right) l_{r}=0
\end{aligned}
$$

where the state relation can further be related as:

$$
\begin{aligned}
& \dot{x}_{3}=x_{1}-l_{f} x_{2}-v_{i n 1} \\
& \dot{x}_{4}=x_{1}+l_{r} x_{2}-v_{i n 2}
\end{aligned}
$$

The equations of motion for passive system can be easily obtained from the same figure by letting $c_{o f f 1}=c_{s 1}$, $c_{o n 1}=c_{s 1}, c_{o f f 2}=c_{s 2}$ and $c_{o n 2}=c_{s 2}$. Semiactive control policy can be easily summarized in a typical quarter-car two-degree-of-freedom model as having the following conditions [3]:

$$
\begin{aligned}
& v_{1} v_{12} \geqslant 0 c_{s a}=c_{\max }=c_{o n} \quad(\text { high }- \text { statedamping }) \\
& v_{1} v_{12}<0 c_{s a}=c_{\min }=c_{o f f} \quad(\text { low }- \text { statedamping })
\end{aligned}
$$

where relative velocity, $v_{12}$ is defined as the velocity of the sprung mass, $m_{s}$ relative to unsprung mass, $m_{u}$, i.e. $v_{12}=v_{1}-v_{2}$.

Mean square response can be obtained by using the following relationship:

$$
E\left[y^{2}\right]=S_{0} \int_{-\infty}^{\infty}\left|H_{y}(\omega)\right|^{2} d \omega
$$

where $S_{0}$ is the spectral density of the white-noise input, and $H_{y}(\omega)$ is the transfer function relating the response variable $y$ to the white-noise input [1].

The motion variables of interest in this analysis are the vertical velocity of the sprung mass, $x_{1}$, the pitch angular velocity of the sprung mass, $x_{2}$, and the front and rear deflection of the suspension, $x_{3}$ and $x_{4}$, respectively.

Transforming these equations of motion into the $s$ domain using Laplace transform and rearrange the variables, transfer functions of interest can then be obtained. The transfer functions of interest are sprung mass vertical velocity, $H_{x_{1}}(s)=\frac{x_{1}}{v_{i_{n}}}(s)$, sprung mass pitch angular velocity, $H_{x_{2}}(s)=\frac{x_{2}}{v_{i n}}(s)$, and front and rear suspension deflections, $H_{x_{3}}(s)=\frac{x_{3}}{\dot{v}_{i n}}(s)$, and $H_{x_{4}}(s)=\frac{x_{4}}{\dot{v}_{i n}}(s)$, respectively.

Two types of input velocity are used in this work. The first type is called heave input signal, where $v_{i n 1}=v_{i n 2}=$ $v_{i n}$, and the second type is pitch input signal, where $v_{i n 1}=v_{i n}, v_{i n 2}=-v_{i n}$. The input is illustrated in Fig. 2.

Asami and Nishihara [11] have shown that the mean square response of the system, i.e. solution for Eq. (6) can be obtained by using the residue integration formula. In order to use this formula, $\left|H_{y}(\omega)\right|^{2}$ which is the square of the transfer function must be arranged in the following form, letting $T(\omega)$ as $\left|H_{y}(\omega)\right|^{2}$ :

$$
\left|H_{y}(\omega)\right|^{2}=T(\omega)=\frac{a_{1} \omega^{6}+a_{2} \omega^{4}+a_{3} \omega^{2}+a_{4}}{\left(\omega^{4}-b_{2} \omega^{2}+b_{4}\right)^{2}+\left(b_{1} \omega^{3}+b_{3} \omega\right)^{2}}
$$

It should be noted that $\int_{-\infty}^{\infty} T(\omega) d \omega$ is always defined when $T(\omega)$ has the form shown in Eq. (7) and $b_{4} \neq 0$. The expression in Eq. (7) can be expanded and expressed as a function of its 4 pairs of complex conjugate poles $\left( \pm \mathrm{j} \omega_{1}\right.$, $\pm \mathrm{j} \omega_{2}, \pm \mathrm{j} \omega_{3}$, and $\left.\pm \mathrm{j} \omega_{4}\right)$,

$$
T(\omega)=\frac{a_{1} \omega^{6}+a_{2} \omega^{4}+a_{3} \omega^{2}+a_{4}}{\left(\omega^{4}+j b_{1} \omega^{3}-b_{2} \omega^{2}-j b_{3} \omega+b_{4}\right)+\left(\omega^{4}-j b_{1} \omega^{3}-b_{2} \omega^{2}+j b_{3} \omega+b_{4}\right)}
$$


Table 2

Model parameters

\begin{tabular}{lll}
\hline Symbol & Description & Units \\
\hline$m_{s}$ & Sprung mass & $730 \mathrm{Kg}$ \\
$\mathrm{I}_{y y}$ & Pitch moment of inertia & $2460 \mathrm{Kg} \mathrm{m}$ \\
$k_{s 1}$ & Front stiffness coefficient & $17500 \mathrm{~N} / \mathrm{m}$ \\
$k_{s 2}$ & Rear stiffness coefficient & $17500 \mathrm{~N} / \mathrm{m}$ \\
$l_{f}$ & Longitudinal distance from sprung mass C.G. to the front axle & $1.011 \mathrm{~m}$ \\
$l_{r}$ & Longitudinal distance from sprung mass C.G. to the rear axle & $1.803 \mathrm{~m}$ \\
\hline
\end{tabular}

The coefficients $b_{1}, b_{2}, b_{3}$ and $b_{4}$ can be expressed as a function of the poles, $\omega_{1}, \omega_{2}, \omega_{3}$, and $\omega_{4}$. This is shown below,

$$
\begin{aligned}
& b_{1}=\omega_{1}+\omega_{2}+\omega_{3}+\omega_{4} \\
& b_{2}=\omega_{1} \omega_{2}+\omega_{1} \omega_{3}+\omega_{1} \omega_{4}+\omega_{2} \omega_{3}+\omega_{2} \omega_{4}+\omega_{3} \omega_{4} \\
& b_{3}=\omega_{1} \omega_{2} \omega_{3}+\omega_{1} \omega_{2} \omega_{4}+\omega_{1} \omega_{3} \omega_{4}+\omega_{2} \omega_{3} \omega_{4} \\
& b_{4}=\omega_{1} \omega_{2} \omega_{3} \omega_{4}
\end{aligned}
$$

Substituting these relationships to Eq. (8) yields,

$$
T(\omega)=\frac{a_{1} \omega^{6}+a_{2} \omega^{4}+a_{3} \omega^{2}+a_{4}}{\left(\omega+j \omega_{1}\right)\left(\omega-j \omega_{1}\right)\left(\omega+j \omega_{2}\right)\left(\omega-j \omega_{2}\right)\left(\omega+j \omega_{3}\right)\left(\omega-j \omega_{3}\right)\left(\omega+j \omega_{4}\right)\left(\omega-j \omega_{4}\right)}
$$

Now, the integral $\int_{-\infty}^{\infty} T(\omega) d \omega$ can be expressed as a function of $\omega_{1}, \omega_{2}, \omega_{3}$, and $\omega_{4}$ by using the Residue integration formula.

$$
\int_{-\infty}^{\infty} T(\omega) d \omega=2 \pi j \sum \operatorname{Res}[T(\omega)]
$$

where Res $[T(\omega)]$ denotes a residue of $T(\omega)$ corresponding to a pole of $T(\omega)$ located in the upper-half of the complex plane [11]. Also, $\omega_{1}, \omega_{2}, \omega_{3}$, and $\omega_{4}$ are positive numbers because the coefficients $b_{1}, b_{2}, b_{3}$ and $b_{4}$ that are obtained when deriving Eq. (7) are always positive.

$$
\int_{-\infty}^{\infty} T(\omega) d \omega=2 \pi j \sum_{k=1}^{n} \lim \left(\omega-i \omega_{k}\right) T(\omega)
$$

the mean square response of the system can be given as the following relationship.

$$
\int_{-\infty}^{\infty} T(\omega) d \omega=\pi \frac{a_{1} b_{4}\left(-b_{1} b_{4}+b_{2} b_{3}\right)+a_{2}\left(b_{3} b_{4}\right)+a_{3}\left(b_{1} b_{4}\right)+a_{4}\left(b_{1} b_{2}-b_{3}\right)}{b_{4}\left(b_{1} b_{2} b_{3}-b_{3}^{2}-b_{1}^{2} b_{4}\right)}
$$

The same model parameters are used for every configuration. Their numerical values are summarized in Table 2 . All analyses conducted in this work are done using MATLAB software. MATHEMATICA were frequently used to derive the symbolic relations and the mean square equation for the simulation. Using MATLAB built-in function, the natural frequencies of the system for both passive and semi-active are obtained as $\omega_{n 1}=5.06 \mathrm{rad} / \mathrm{s}$ and $\omega_{n 2}=$ $7.27 \mathrm{rad} / \mathrm{s}$.

The transmissibility ratios for each of the state variable for various damping coefficients and input types are first presented. Each semi-active control technique is compared along with the conventional passive system. Then the rms values are obtained using Eq. (16).

In the following section, the frequency responses of the passive and semi-active control systems are initially presented. There different damping coefficient values are shown to indicate the curve trend as the value is varied. For the passive case, the three values of damping are: 


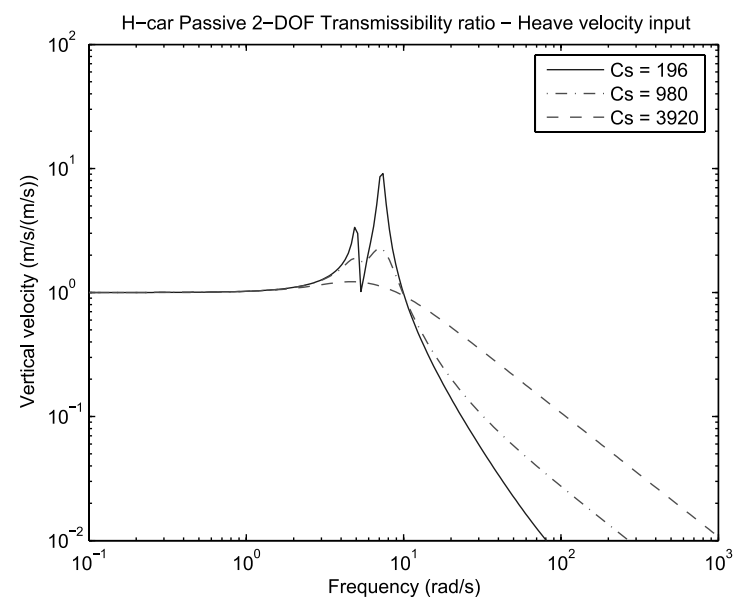

(a) Passive - Heave velocity input

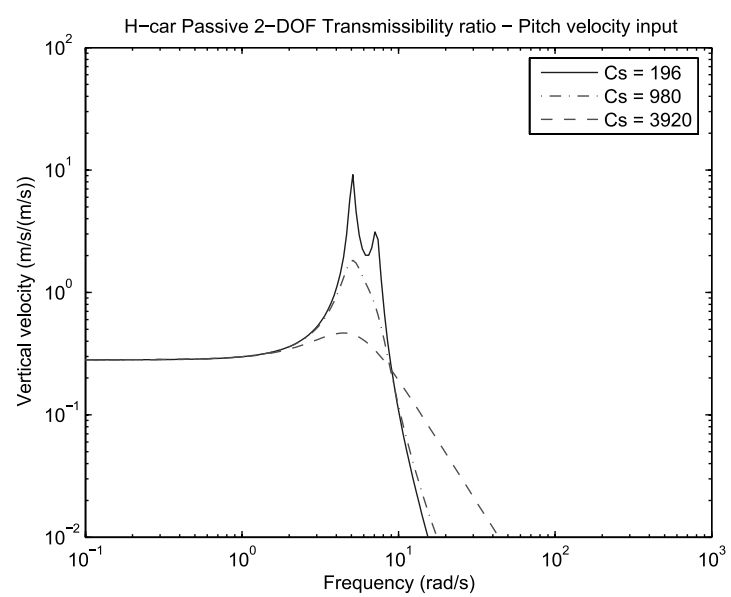

(a) Passive - Pitch velocity input

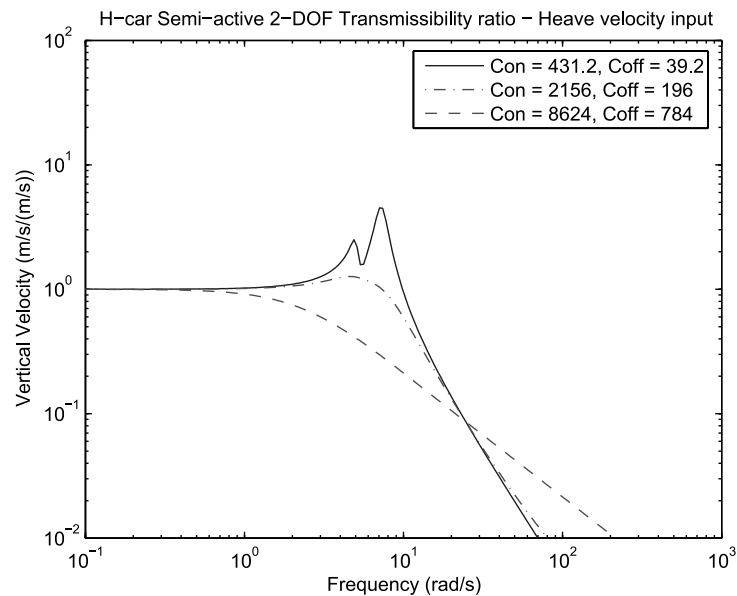

(b) Semi-active - Heave velocity input

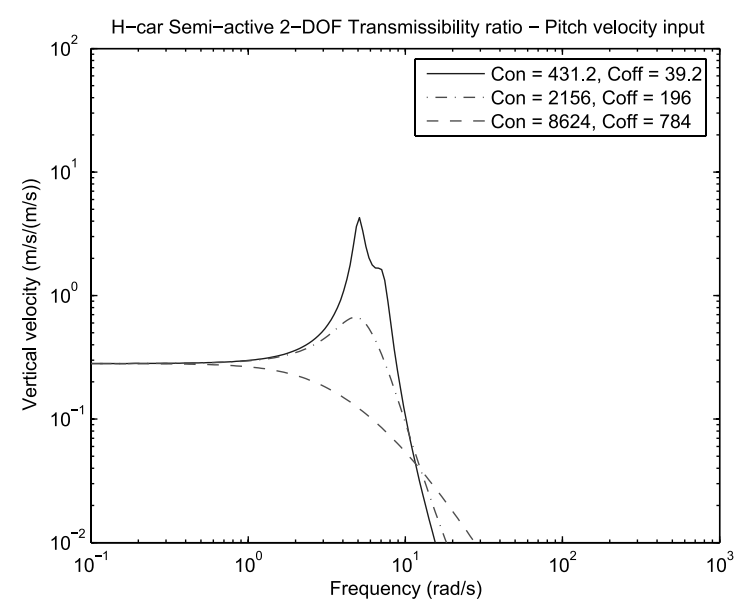

(d) Semi-active - Pitch velocity input

Fig. 3. Transmissibility ratio of vertical velocity for various damping coefficients.

- $c_{s 1}=c_{s 2}=196^{N} \cdot s / \mathrm{m}$ which correspond to a lightly damped suspension.

- $c_{s 1}=c_{s 2}=980^{N} \cdot s / m$ which correspond to a typical damping value for passenger cars.

$-c_{s 1}=c_{s 2}=3920^{N} \cdot s / \mathrm{m}$ which correspond to a heavily damped suspension.

Typical semi-active damping coefficients are chosen using the relationships of $c_{\text {on }}=2.2 c_{s}$ and $c_{o f f}=0.2 c_{s}$ [2]. These relationships yield to $\left(c_{o n}-c_{o f f}\right)=2 c_{s}$. Thus, the pairs of damping coefficients used for plotting the frequency responses will therefore be:

$-c_{o n 1}=c_{o n 2}=431.2^{N \cdot s} / \mathrm{m}$ and $c_{o f f 1}=c_{o f f 2}=39.2^{N \cdot s} / \mathrm{m}$ for a lightly damped suspension

$-c_{o n 1}=c_{o n 2}=2156^{N \cdot s} / \mathrm{m}$ and $c_{o f f 1}=c_{o f f 2}=196^{N} \cdot \mathrm{s} / \mathrm{m}$ for a typical damping value for passenger cars

$-c_{o n 1}=c_{o n 2}=8624^{N} \cdot \mathrm{s} / \mathrm{m}$ and $c_{o f f 1}=c_{o f f 2}=784^{N} \cdot \mathrm{s} / \mathrm{m}$ for a heavily damped suspension

The next analysis is to study the relationship of root mean square (rms) of the state variables. Four different comparisons are made, namely:

1. rms pitch angular acceleration versus rms vertical acceleration

2. rms rear suspension deflection versus rms front suspension deflection 


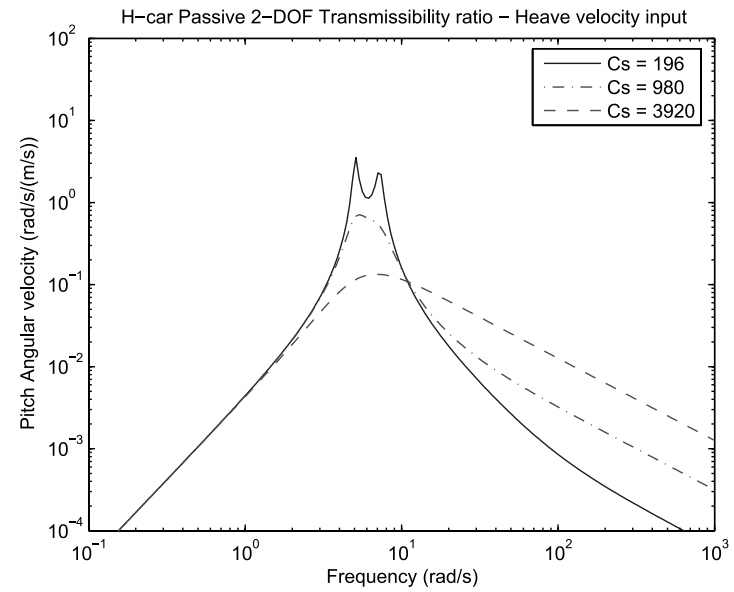

(a) Passive - Heave velocity input

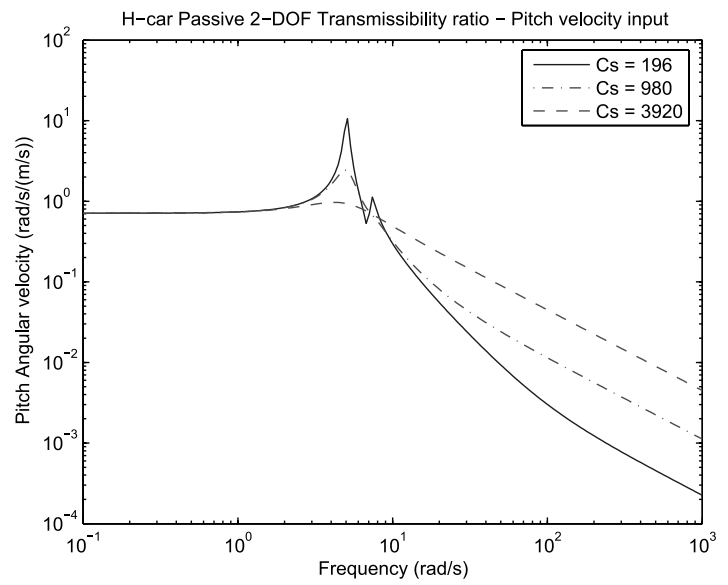

(a) Passive - Pitch velocity input

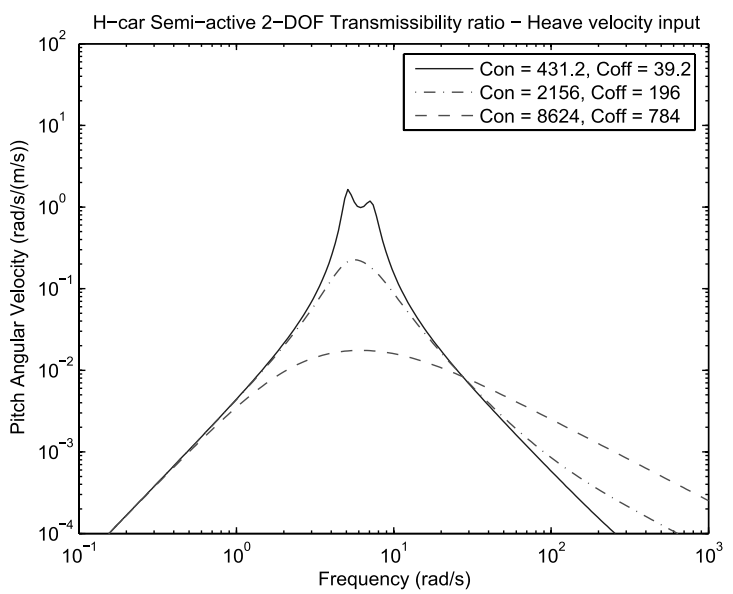

(b) Semi-active - Heave velocity input

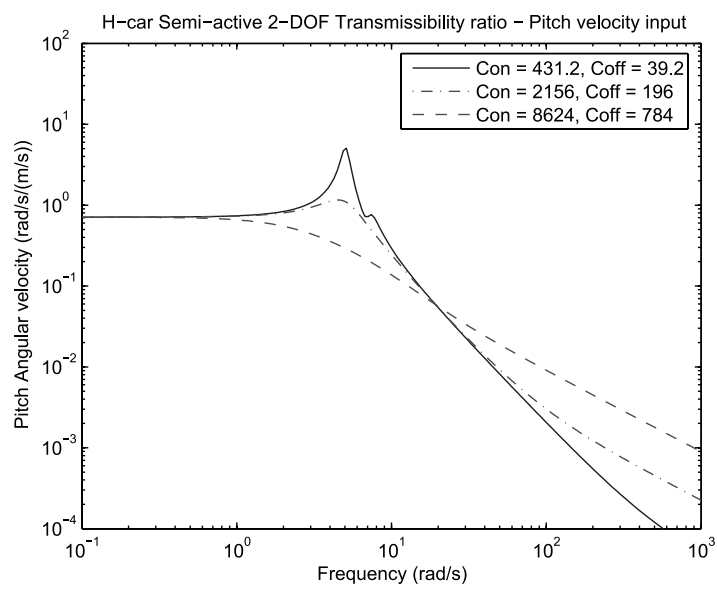

(d) Semi-active - Pitch velocity input

Fig. 4. Transmissibility ratio of pitch angular velocity for various damping coefficients.

3. rms pitch angular acceleration versus rms front suspension deflection

4. rms vertical acceleration versus rms front suspension deflection

For each plot, the influence of the damping coefficient and the suspension's stiffness is displayed. The vehicle is assumed to travel at a constant speed on a random road surface. The same model parameters were used as in Table 2, except the spring stiffness, which was varied. For the purpose of representing it as a spring ratio, $r_{k}$, the 'tire' stiffness was taken as $175000 \mathrm{~N} / \mathrm{m}$. This $r_{k}$ values was varied from 5 representing soft spring to 20 representing stiff spring. For each value of $r_{k}$, various damping ratio, $\zeta_{s}$ were used, varies from 0.05 as a lightly damped to 1 as a heavily damped system.

\section{Results and discussion}

\subsection{Frequency response analysis}

Figures 3-6 show the transmissibility ratio of the sprung mass vertical velocity, pitch angular velocity, the transmissibility ratio of the front and the rear suspension deflection, respectively. All plots show that increasing the 


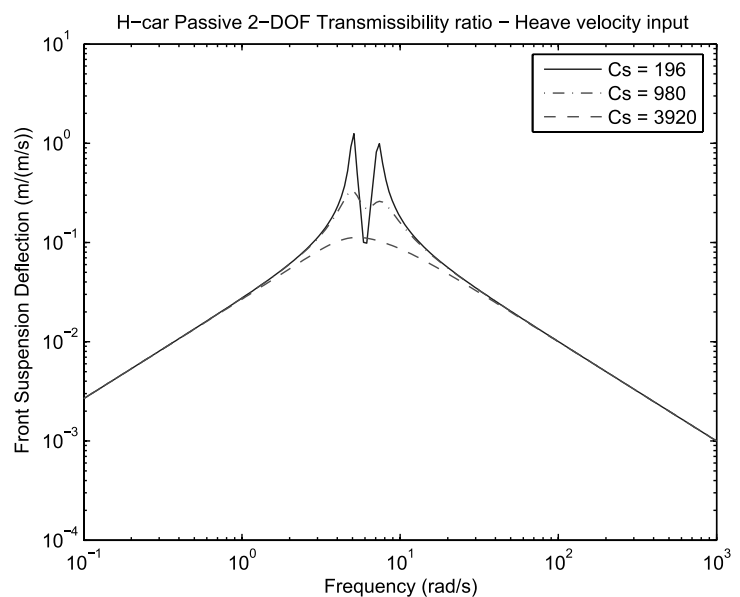

(a) Passive - Heave velocity input

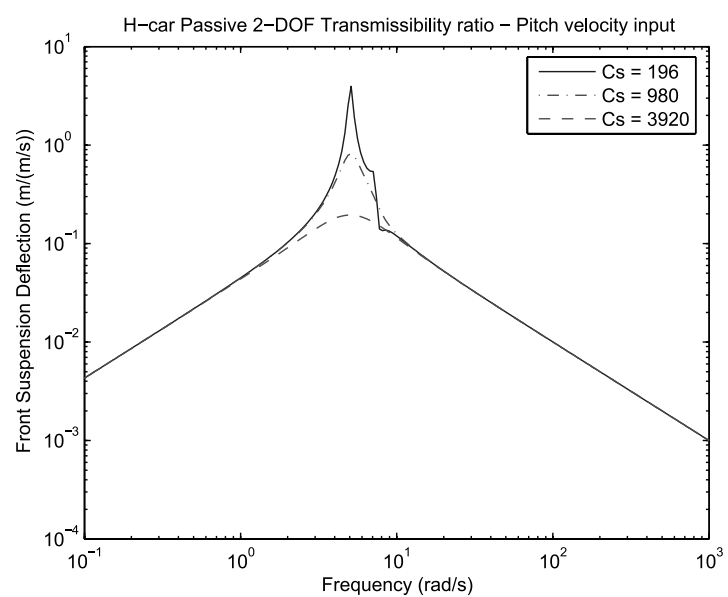

(c) Passive - Pitch velocity input

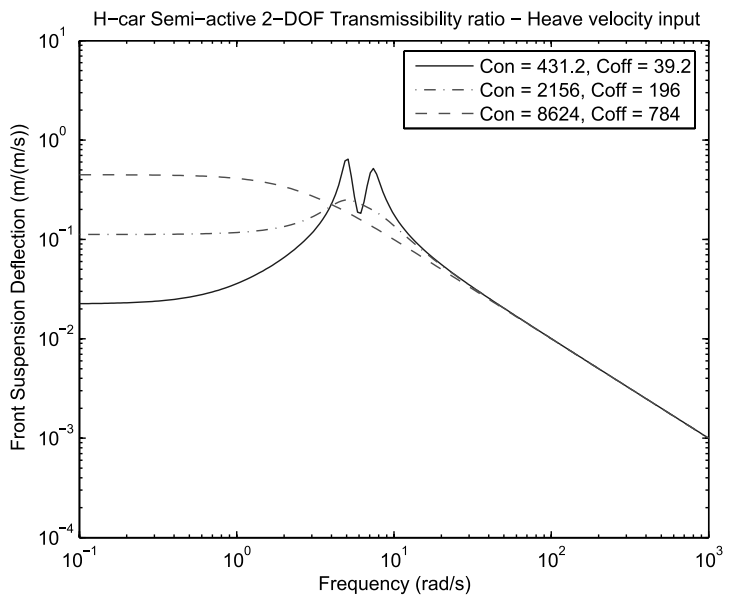

(b) Semi-active - Heave velocity input

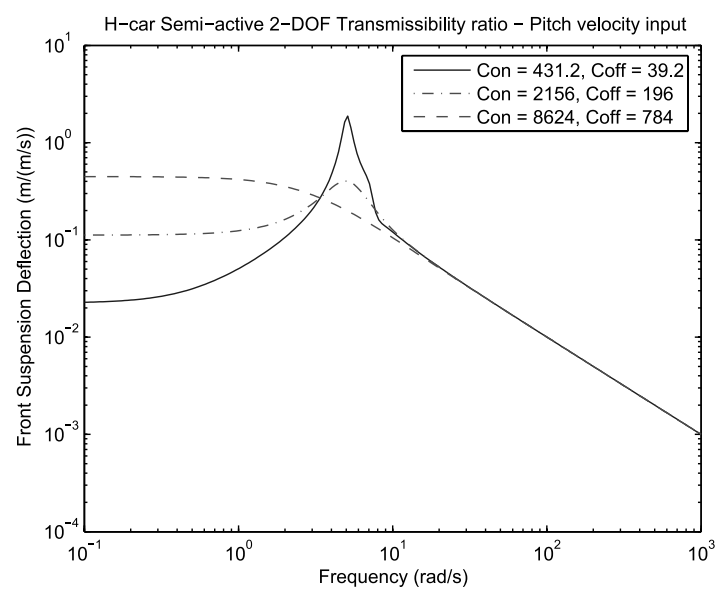

(d) Semi-active - Pitch velocity input

Fig. 5. Transmissibility ratio of front suspension deflection for various damping coefficients.

damping coefficient reduces the response value at the sprung mass natural frequencies $\omega_{n 1}$ (pitch natural frequency) and $\omega_{n 2}$ (heave natural frequency).

Figures 3 and 4 show that as the damping coefficient is increased the responses are exactly the same at frequencies lower than the natural frequencies while tend to increase at higher frequencies. On the other hand, Figs 5-6 show that as the frequency increases beyond the natural frequencies, the responses seem to converge towards the same point for all damping coefficient. However at frequencies lower than the natural frequencies, while the responses for passive system tend to converge towards the same point, the responses for the semi-active system approaches a constant value. This constant value tends to further increase as the coefficient increase.

Comparing between the passive and semi-active systems, in all cases, the peak values for both heave and pitch inputs is lower in the semi-active cases.

\subsection{RMS analysis}

Figure 7 shows the relationship between the rms pitch angular velocity and the rms vertical velocity for both passive and semi-active systems with the two types of input signals. Figure 7(a) and 7(c) shows that for the passive suspension system with heave velocity input and pitch velocity input, increasing the damping coefficient from a low 


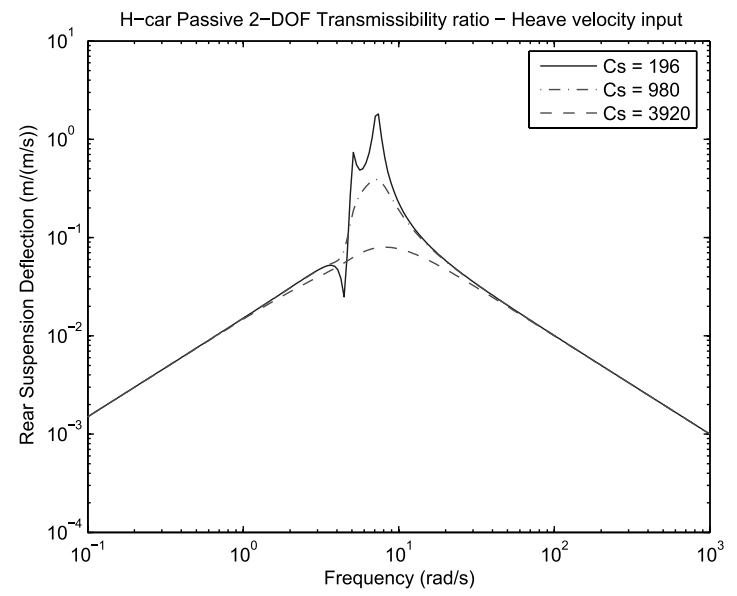

(a) Passive - Heave velocity input

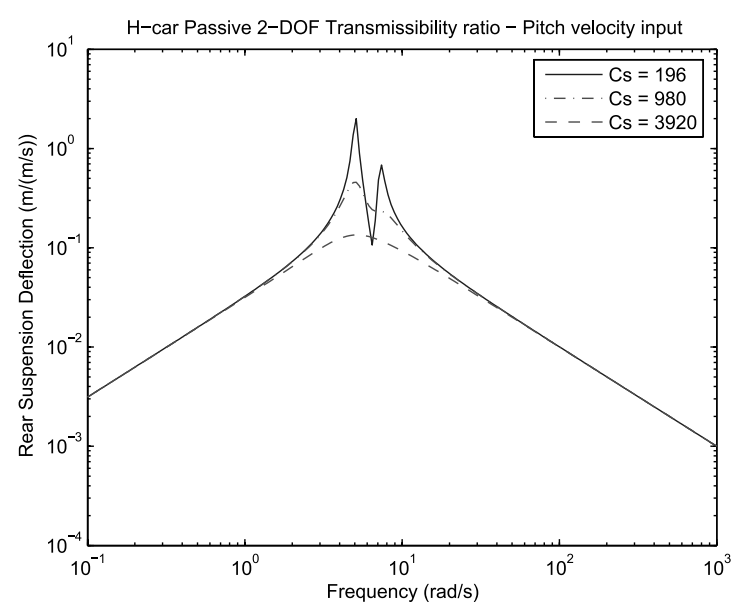

(c) Passive - Pitch velocity input

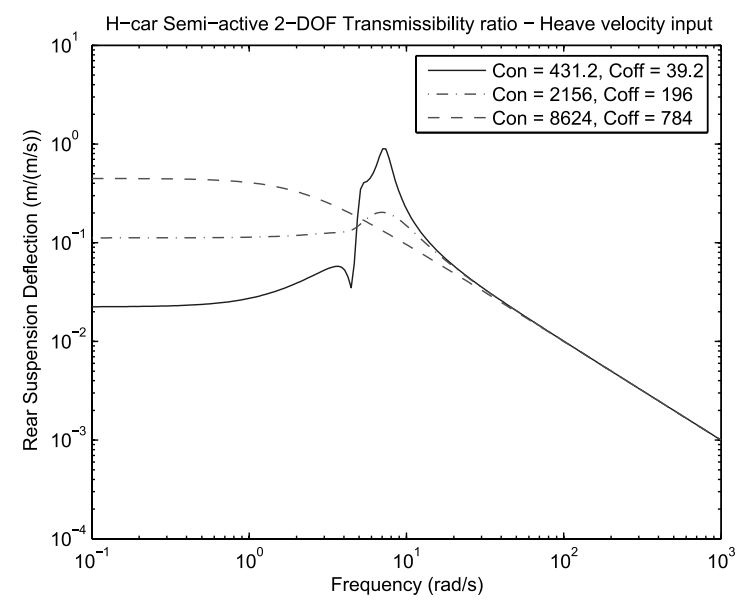

(b) Semi-active - Heave velocity input

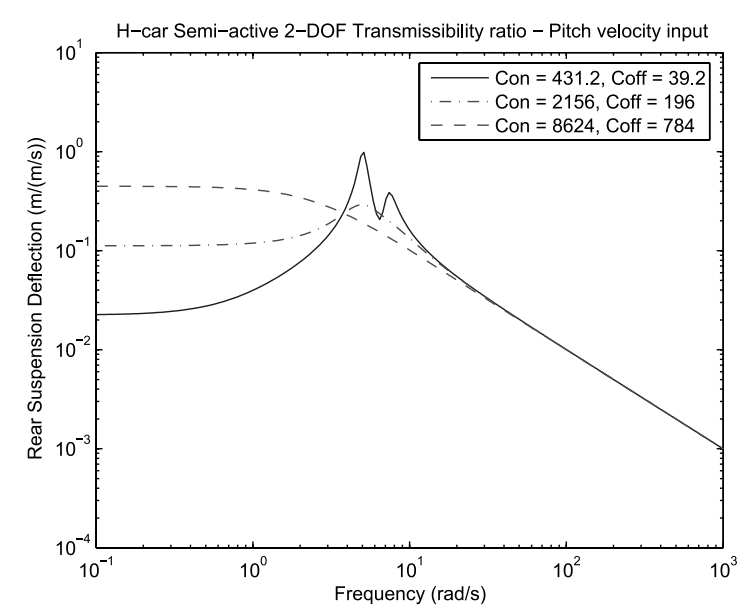

(d) Semi-active - Pitch velocity input

Fig. 6. Transmissibility ratio of rear suspension deflection for various damping coefficients.

value to a midrange value causes to lower the rms pitch angular velocity and rms vertical velocity. Increasing the damping further results in an increase in rms pitch angular velocity, and even more increase for rms vertical velocity in the heave velocity input case. The opposite trend is observed in the pitch velocity input, whereby more significant increase occurs in rms pitch angular velocity than in rms vertical velocity.

This influence of damping coefficient in the rms value can be understood by referring back to the transmissibility ratio plots discussed earlier. For the passive systems, Fig. 3(a) and 3(c), increasing the damping coefficient reduces the peak values of vertical velocity at the natural frequencies, but at the same time increases the values at higher frequencies. Increasing the damping coefficient therefore, could initially reduce the rms value of the vertical velocity, as the reduction in the peak values at the natural frequencies is more significant than the increase values at higher frequencies. However, further increase in the coefficient would increase the rms values as the increasing values at higher frequencies become relatively more significant.

For the semi-active system with heave velocity input, Fig. 7(b) and 7(d), increasing the damping coefficient decreases the rms pitch angular velocity as well as the rms vertical velocity. As the coefficient is further increased, the rms values are further decrease, with less rapidly for the pitch angular velocity but more rapidly for the vertical velocity in the case of heave input. The opposite trend is observed in the pitch input case - decrease more rapidly for the pitch angular velocity and less rapidly for the vertical velocity. 


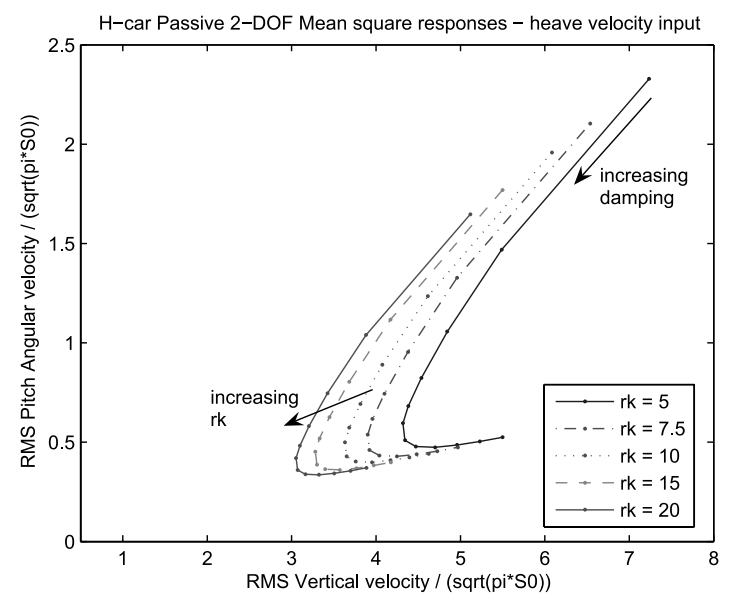

(a) Passive - Heave velocity input

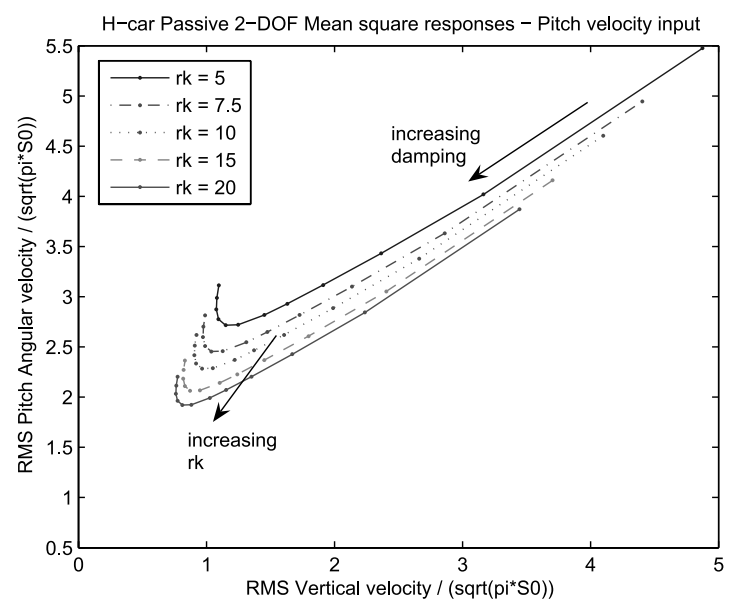

(c) Passive - Pitch velocity input

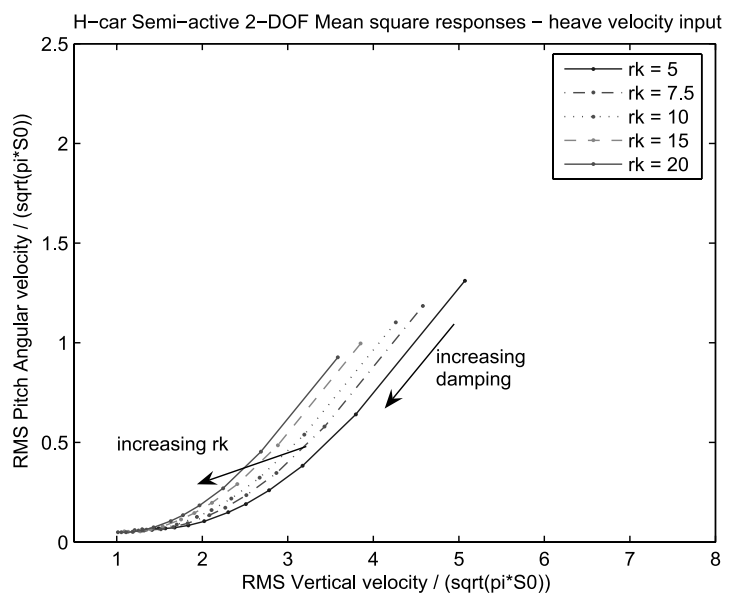

(b) Semi-active - Heave velocity input

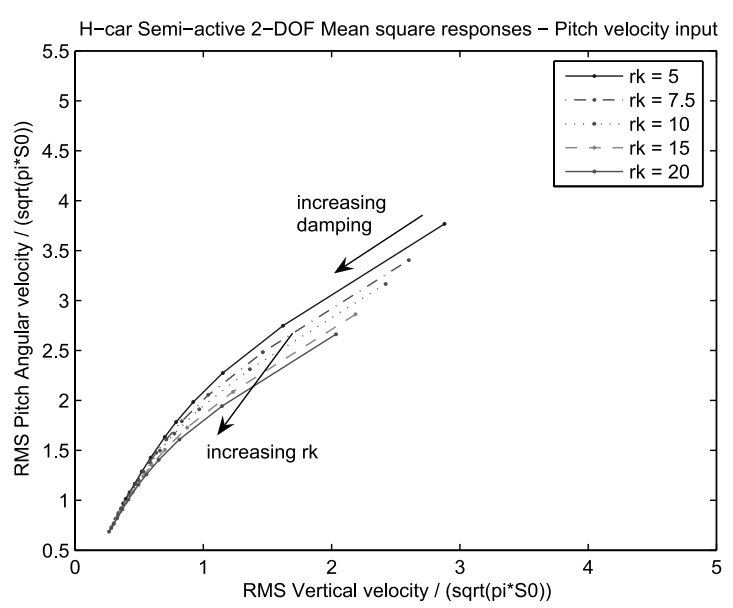

(d) Semi-active - Pitch velocity input

Fig. 7. Relationship between the rms pitch angular velocity to rms vertical velocity.

Comparing the RMS values between the passive and semi-active responses, semi-active control scheme shows significant reduction in the rms values for all values of the damping coefficient. And the increase in stiffness ratio, $r_{k}$, decreases both the rms pitch angular velocity and the rms vertical velocity in the passive and semi-active systems.

Figure 8 shows the relationship between the rms rear suspension deflection and the rms front suspension deflection for both passive and semi-active systems with the two types of input signals. First, Fig. 8(a) and 8(c) show that for the passive suspension system, both heave velocity input and pitch velocity input, increasing the damping coefficient value lowers the rms rear suspension deflection as well as the front suspension deflection.

Figure 8(b) and 8(d) show that for the semi-active system, increasing the damping coefficient from a low value to a midrange value significantly decreases both the rms front suspension deflection and rms rear suspension deflection. As the coefficient is further increased, significant increase occur in both cases as well.

Second, comparing the rms values between the passive and semi-active responses, semi-active control scheme significantly reduces the rms values for a low value to a midrange value of the damping coefficient. However, as the coefficient is further increase, passive system performs better as the rms values are further reduced while the rms for the semi-active system increased. And finally, the increase in stiffness ratio, $r_{k}$, increases both the rms rear suspension deflection and the rms front suspension deflection in the passive and semi-active systems. 


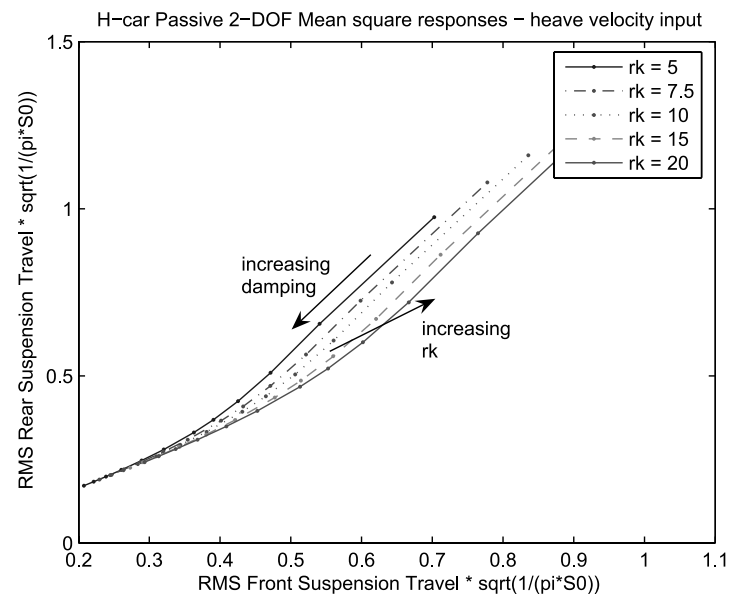

(a) Passive - Heave velocity input

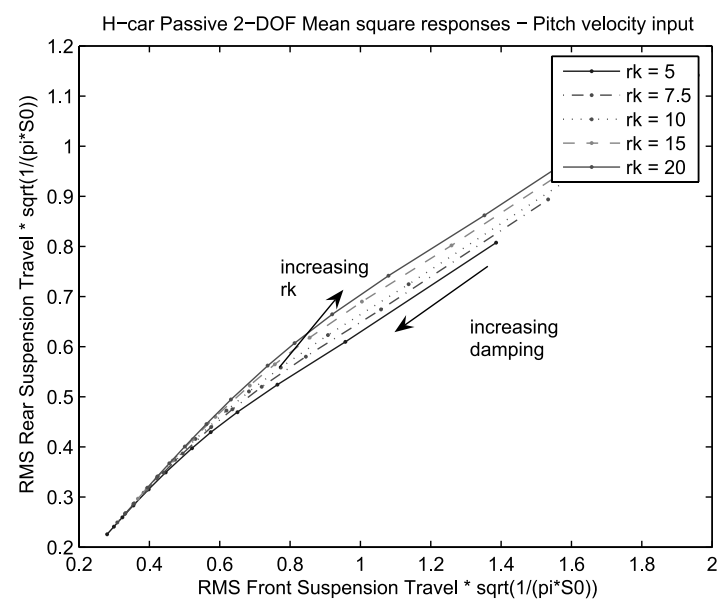

(c) Passive - Pitch velocity input

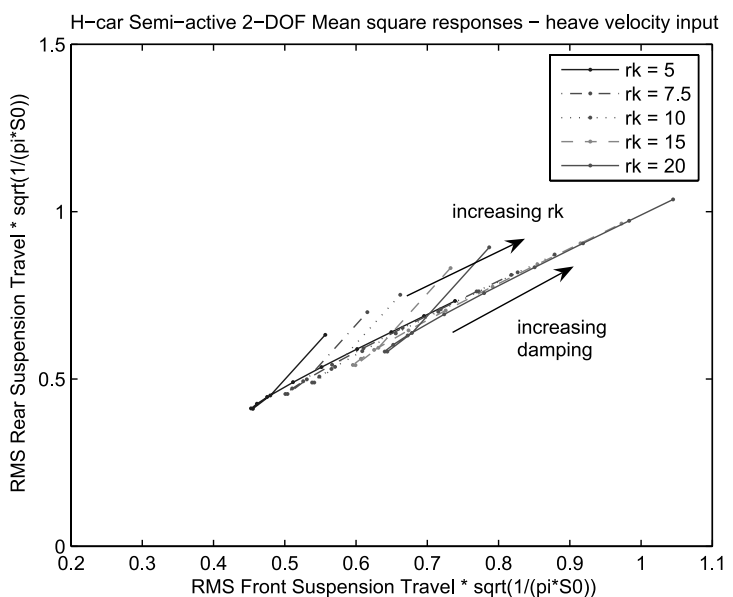

(b) Semi-active - Heave velocity input

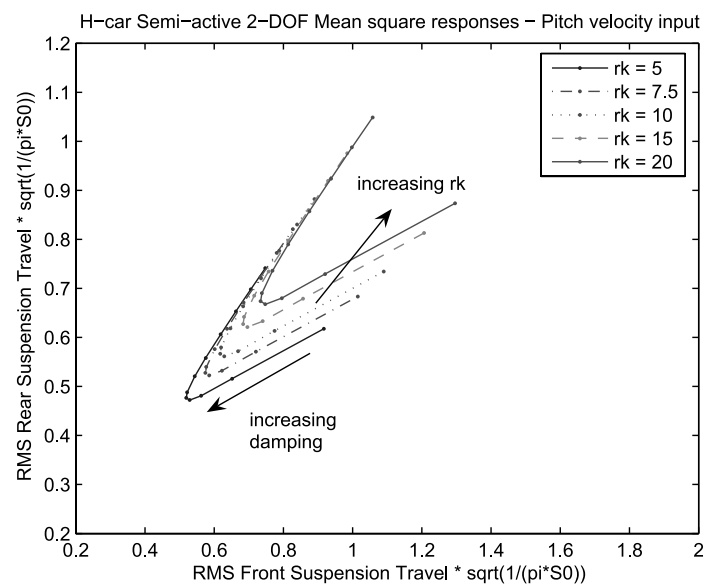

(d) Semi-active - Pitch velocity input

Fig. 8. Relationship between the rms rear suspension deflection to rms front suspension deflection.

Figure 9 shows the relationship between the rms vertical velocity and the rms front suspension deflection for passive system with the two types of input signals. Figure 9(a) shows that for the passive suspension system with heave velocity input, increasing the damping coefficient from a low value to a midrange value reduces the rms vertical velocity and the rms front suspension deflection. However, while increasing the damping further results in an increase in the rms vertical velocity, the rms front suspension deflection further reduces. In Fig. 9(b), the pitch velocity input causes a slight increase in the rms vertical velocity while the rms front suspension deflection further reduces. This is in agreement with the corresponding transmissibility ratio plots for each state variable as previously discussed.

For the semi-active system, increasing the damping coefficient from a low value to a midrange value reduces the rms vertical velocity and the rms front suspension deflection. However, while increasing the damping further results in a significant increase in the rms front suspension deflection, the rms vertical velocity further decreases. Less significant decrease of the rms vertical velocity is observed in the pitch velocity input than the heave velocity input.

Comparing the rms values between the passive and semi-active responses, semi-active control scheme significantly reduces the rms values for a low value to a midrange value of the damping coefficient. However, as the coefficient is further increase, passive system performs better as the rms values are further reduced while the rms for the 


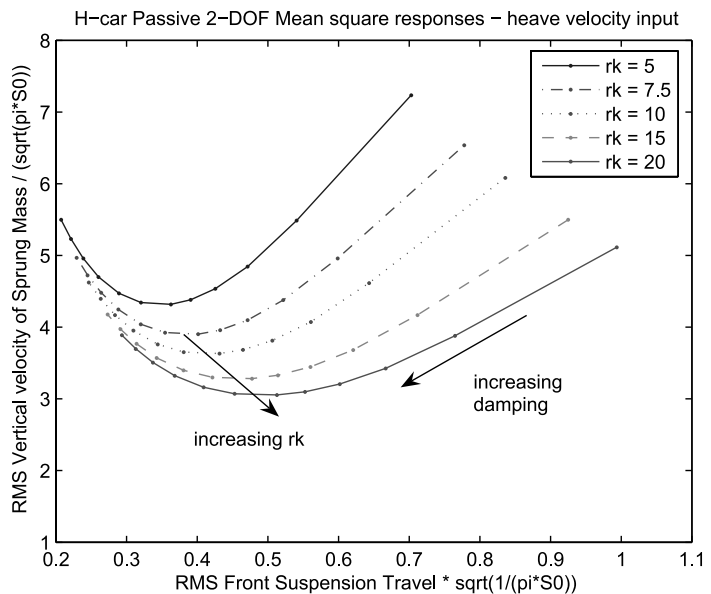

(a) Passive - Heave velocity input

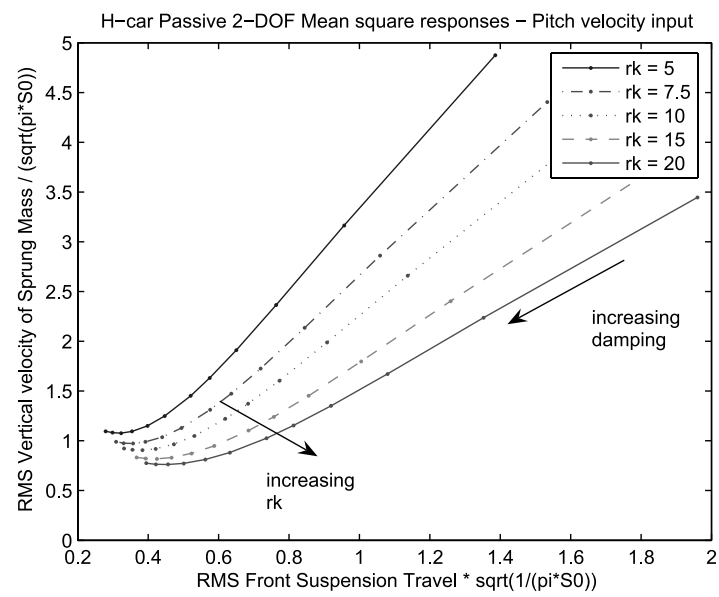

(c) Passive - Pitch velocity input

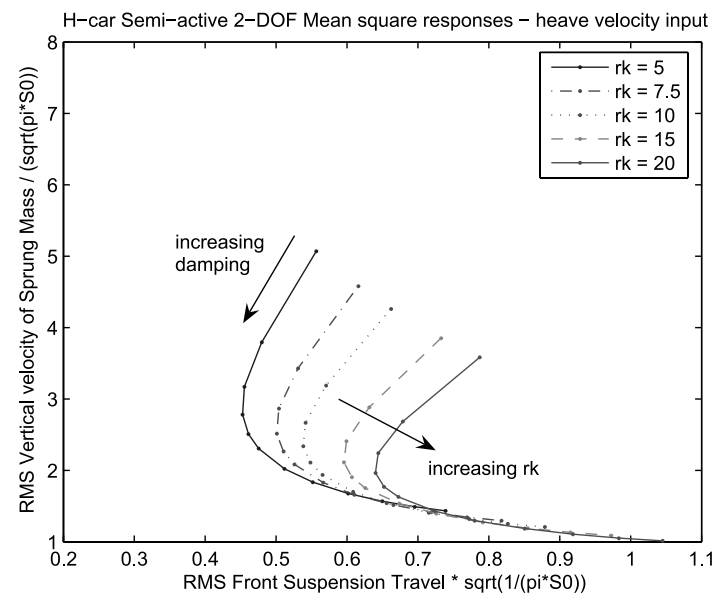

(b) Semi-active - Heave velocity input

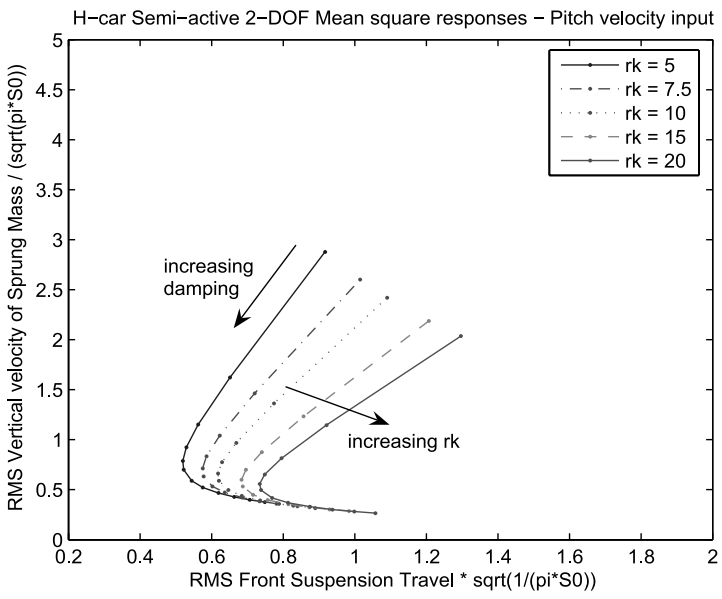

(d) Semi-active - Pitch velocity input

Fig. 9. Relationship between the rms vertical velocity to rms front suspension deflection.

semi-active system increased. Also, the increase in stiffness ratio, $r_{k}$ decreases the rms vertical acceleration while increases the rms front suspension deflection in all cases.

Figure 10(a) shows that for the passive suspension system with heave velocity input, increasing the damping coefficient from a low value to a midrange significantly reduces the rms pitch angular velocity, while relatively slightly reduces the rms front suspension deflection. However, increasing the coefficient further results in an increase in the rms pitch angular velocity, while the rms front suspension deflection further reduces. Almost a similar scenario is observed in the pitch velocity input in Fig. 10(b), but with a relatively more significant increase in the rms pitch angular velocity.

For the semi-active system, increasing the damping coefficient from a low value to a midrange value reduces the rms pitch angular velocity and the rms front suspension deflection. However, while increasing the damping further results in a significant increase in the rms front suspension deflection, the rms pitch angular velocity further decreases. Less significant decrease of the rms pitch angular velocity is observed in the heave velocity input than the pitch velocity input.

Comparing the rms values between the passive and semi-active responses, semi-active control scheme significantly reduces the rms values for a low value to a midrange value of the damping coefficient. However, as the coefficient is further increase, passive system performs better as the rms values are further reduced while the rms for the 


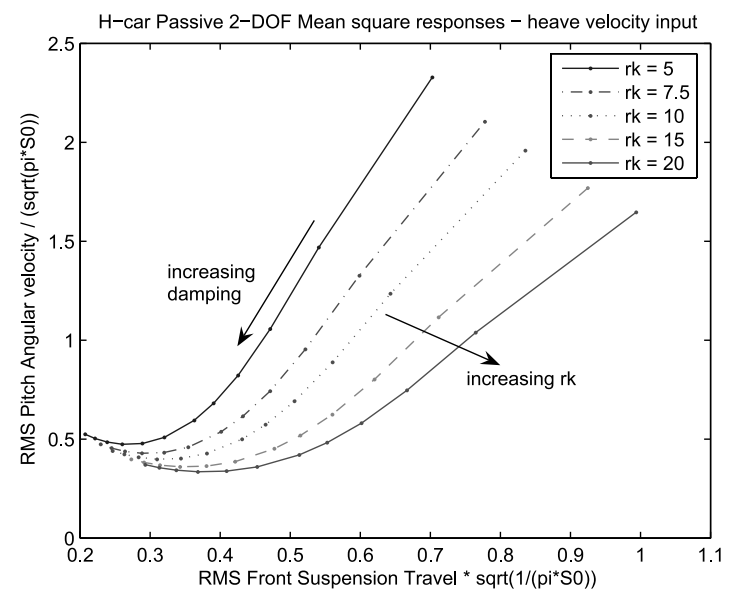

(a) Passive - Heave velocity input

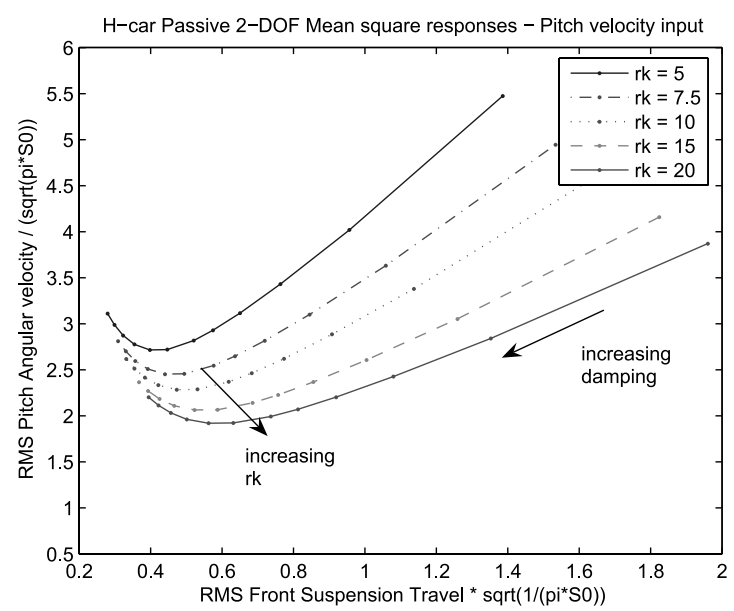

(c) Passive - Pitch velocity input

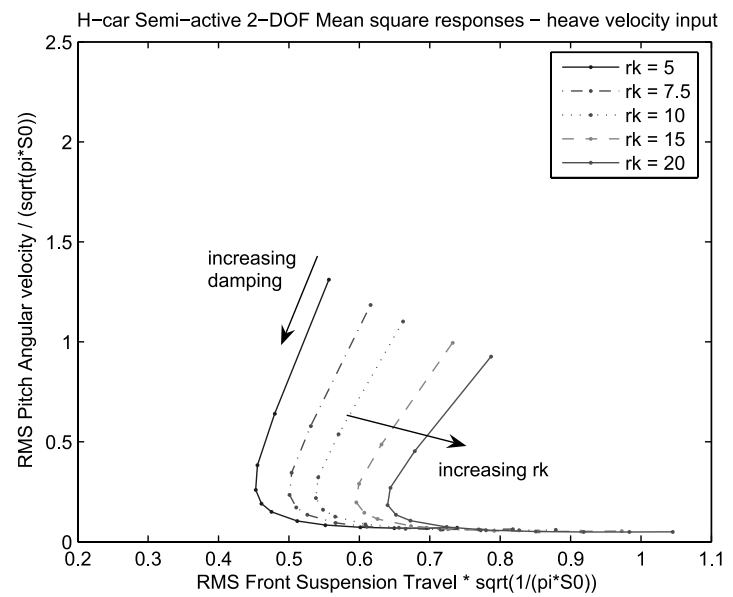

(b) Semi-active - Heave velocity input

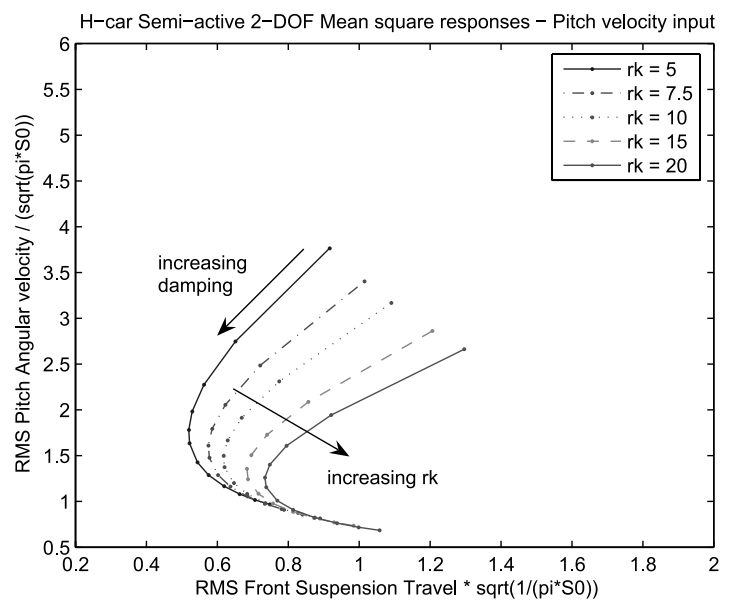

(d) Semi-active - Pitch velocity input

Fig. 10. Relationship between the rms pitch angular velocity to rms front suspension deflection.

semi-active system increased. Lastly, the increase in stiffness ratio, $r_{k}$ decreases the rms pitch angular velocity while increases the rms front suspension deflection in all cases.

\section{Conclusion}

Half-car 2-DOF models were presented and the equations of motion were derived. Residue integration formula for computing the rms value of the transfer functions of the states variables was discussed. Then, the transfer functions of state variables of interest for both passive and semi-active system with different input types were presented and discussed. Using the Residue formula, the root mean square of the transfer functions were obtained and discussed. Results show that significant improvements were achieved in the sprung mass heave and pitch responses using semi-active control scheme. However results for the rear and front suspension deflection show that there are limiting values of damping coefficient beyond which, the semi-active scheme becomes disadvantageous than the passive system.

A potential work as a continuation of this is to separately look at and analyze the tire dynamics model, and later combine the system to the present work by feeding the output of the tire dynamics as an input to it. 


\section{Acknowledgement}

This work is funded by Ministry of Higher Education Malaysia and International Islamic University Malaysia (IIUM) FRGS Research Grant. Part of this work was conducted while the author was at the Advanced Vehicle Dynamics Laboratory, Virginia Tech. (AVDL) as a visiting scholar.

\section{References}

[1] R.M. Chalasani, Ride Performance Potential of Active Suspension Systems - Part I: Simplified Analysis Based on a Quarter-Car Model, ASME Symposium on Simulation and Control of Ground Vehicles and Transportation Systems, AMD-vol. 80, DSC-vol. 2, 1986, pp. 187204.

[2] R.M. Chalasani, Ride Performance Potential of Active Suspension Systems - Part II: Comprehensive Analysis Based on a Full-car Model, Proceedings of 1986 ASME Winter Annual Meeting, Los Angeles, CA, December 1986.

[3] M. Ahmadian, Semiactive Control of Multiple Degree of Freedom Systems, Proceedings of 1997 ASME Design Engineering Technical Conferences, Sacramento, CA, September 1997.

[4] M.J. Crosby and D.C. Karnopp, The Active Damper, The Shock and Vibration Bulletin 43, Naval Research Laboratory, Washington, D.C., 1973.

[5] D.C. Karnopp and M.J. Crosby, System for Controlling the Transmission of Energy between Spaced Members, U.S. Patent 3,807,678, April 1974.

[6] A.K. Carter, Transient Motion Control of Passive and Semiactive Damping for Vehicle Suspensions, Masters Thesis, Virginia Tech., July 1998.

[7] P. Barak, Passive versus Active and Semi-active Suspension from Theory to Application in North American Industry, SAE Technical Paper 922140, 1992.

[8] J.H. Koo, F.D. Goncalves and M. Ahmadian, Investigation of the response time of magnetorheological fluid dampers, Proceedings of SPIE 2004 Smart Structures and Materials/NDE, San Diego, CA, March 2004.

[9] M. Ahmadian, A Hybrid Semiactive Control for Secondary Suspension Applications, Proceerings of 6th ASME Symposium on Advanced Automotive Technologies, Dallas, TX, November 1997.

[10] E.D. Blanchard, On the Control Aspects of Semiactive Suspensions for Automobile Applications, Masters Thesis, Virginia Tech. June 2003.

[11] T. Asami and O. Nishihara, H2 Optimization to Semiactive of the Three-Element Type Dynamic Vibration Absorbers, Journal of Vibration and Acoustics 124(4) (October 2002), 583-592.

[12] S.I. Ihsan, Waleed F. Faris and M. Ahmadian, Dynamics and control policies analysis of semi-active suspension systems using a full-car model, International Journal of Vehicle Noise and Vibration 3(4) (2007), 370-405.

[13] S.I. Ihsan, Waleed F. Faris and M. Ahmadian, Analysis of control policies and dynamic response of a Q-car 2-DOF semi active system, Journal of Shock and Vibration 15(5) (2008), 573-582. 

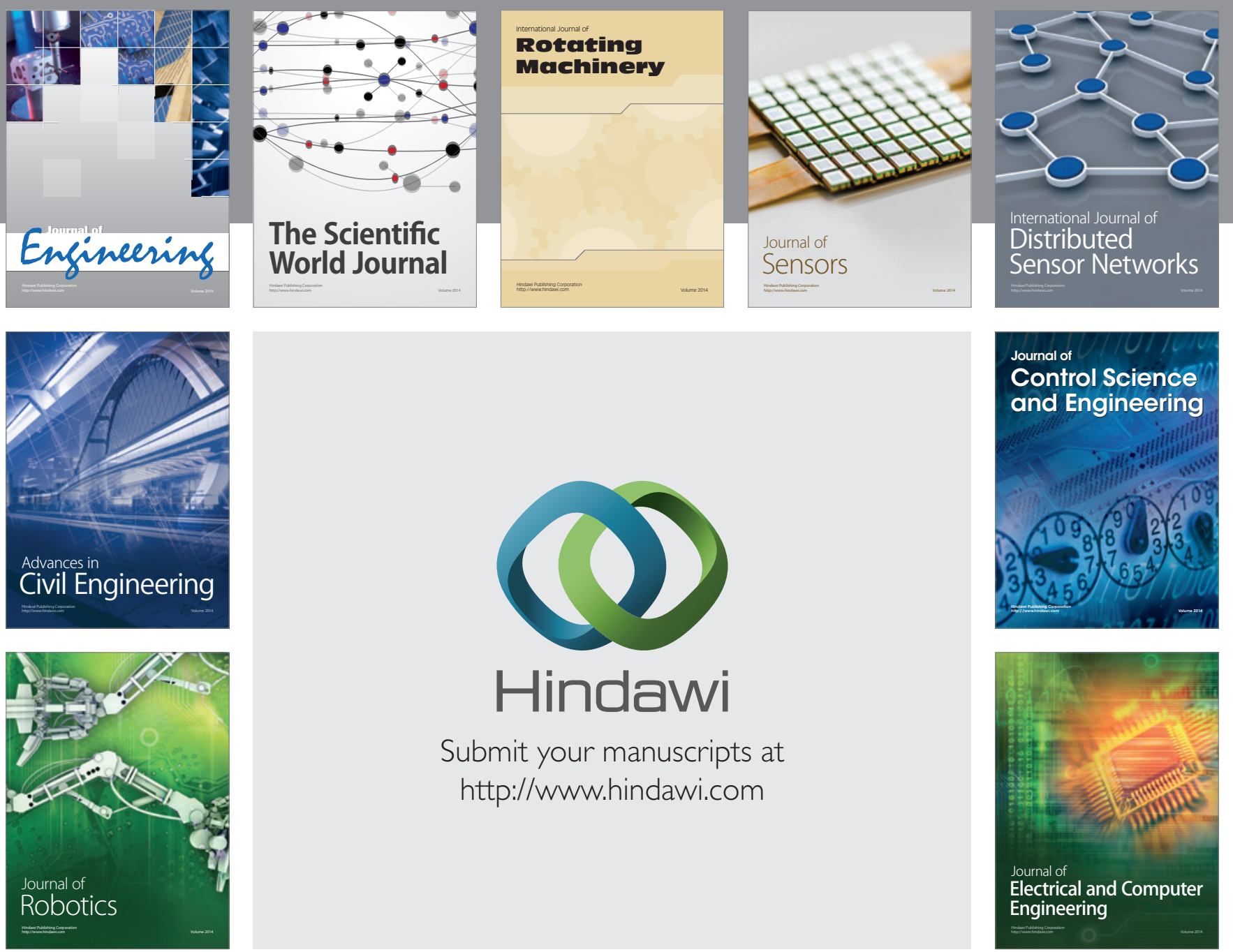

Submit your manuscripts at

http://www.hindawi.com
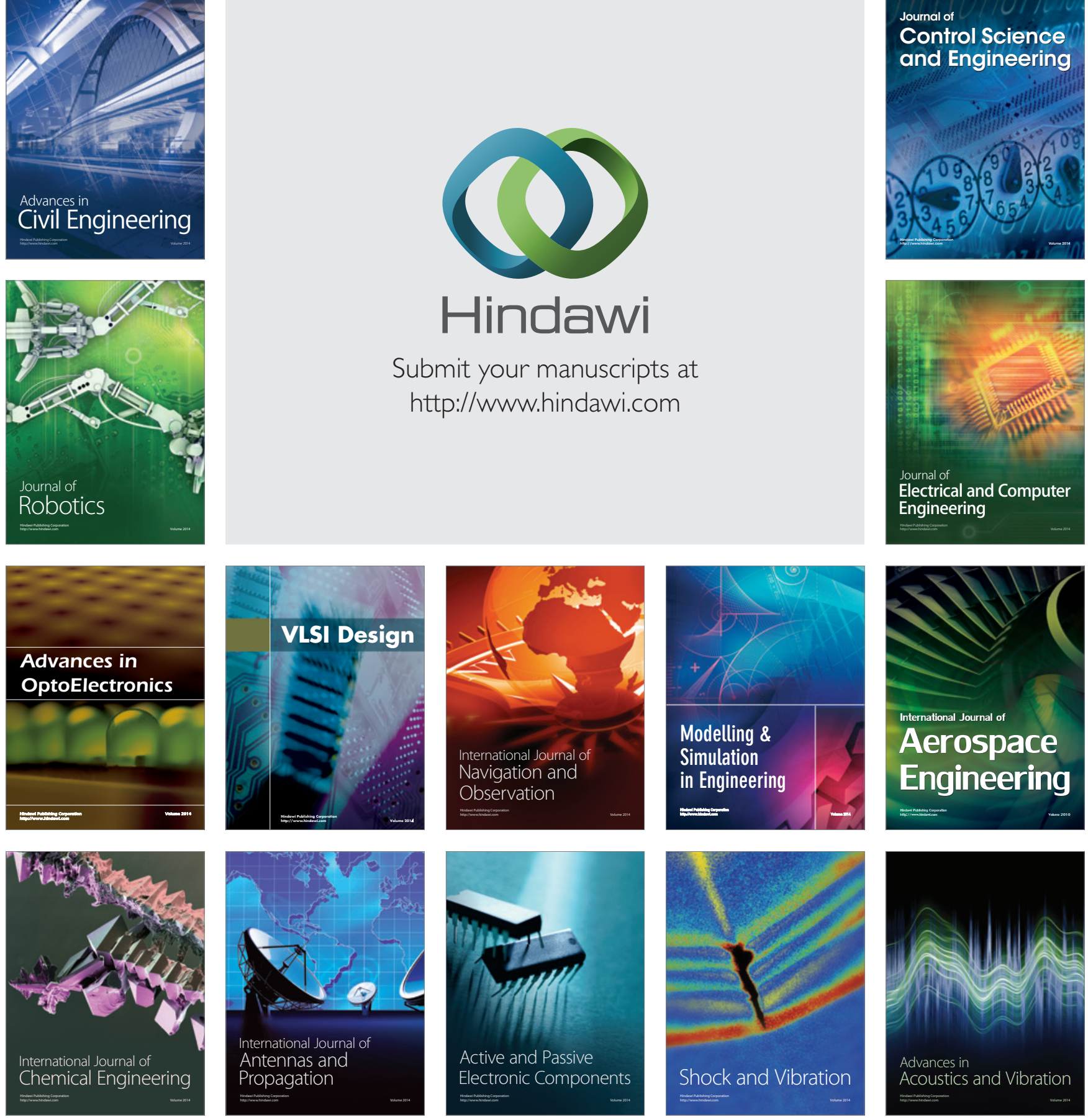